\title{
Changchun College Sports Socialization of Resources Sharing Platform Construction Research
}

\author{
Wang ChangFu \\ Jilin Jianzhu University, Changchun 130021, China
}

Author introduction: Wang Changfu (1973 -), male, Changchun, associate professor;

\begin{abstract}
In national fitness service system based on the gradually perfect, combined with the new period for the masses to provide necessary sports facilities and sports service demand, and defines the college sports resource socialization of sharing platform of fitness service function. To construct the information resources system management software and information resource storage system, the use of computer network and communication system, users to show the resource value of a kind of information resource system management platform structure, the establishment of layered time of college physical education resource sharing system database, formation are adapt to the sports resources management and application service mechanism.
\end{abstract}

KEYWORD: University; Sports resources; Socialized sharing; Platform construction

To further implement the State Council "regulation on public cultural and sports facilities" and "outline of the nationwide body-building plan" the second phase of the project the second phase plan, play school sports venues and public stadium hall effect, efforts to alleviate the problem of insufficient demand sports and fitness facilities of the people's growing[1]. To further promote the national school sports venues open to the community, will be relatively affluent college sports venues resource reasonable use of $\mathrm{Yu}$ Quanmin the fitness of the public service,meet the needs of college sports venues themselves, follow the trend of social development, Changchun City venues for sports resources sustainable development and to better play a beneficial role in the public service to make the University and society, both sides benefit. Need to build the national fitness service system perfect. To improve the state-owned assets investment benefit. Favorable to the construction of the harmonious community, the need of the development of community sports. To establish the concept of modern education, need to fully implement the party's education policy[2].

\section{ROUTE AND METHOD TO DETERMINE THE PLATFORM TECHNOLOGY OF SHARING THE SPORTS RESOURCES}

\subsection{The technical route of sports resources sharing platform}

The use of modern means of information integrate closely related to various colleges and universities sports resources in Changchun City, various venues, facilities, instruments, equipment, buildings, books, sports related to the number of faculty and professional settings, business, and various management activities of all people, property, fabric. Preliminary college sports resources sharing system data base to establish the hierarchical, mutually for the new mechanism of sportsresource management and service adaptation. Do the unified code, unified platformprinciple.

\subsection{The basic method of sports resources sharing platform technology}

1.2.1 Establishing database of sports resource management, comprehensive, accurate, and dynamically reflect changes in the amount of sports resources, composition, distribution, information, etc. Dynamic database according to resources statistical results as the initial data sources, updated in real time according to the change of resource increase or decrease at the same time. 
1.2.2 It is based on the initial database, the establishment of data information query subsystem, and the comprehensive analysis of the public resource in all kinds of information, for inquirers to provide convenient and quick query resources possess, use and changes in real time. Provide information support for the resource usage and optimization.

1.2.3 Sports resources platform is established management procedures, establish the secondary management platform, meet the demand of different levels of management, resource use, optimization, statistics, earnings, cash management content. Implement standardization and institutionalization of the management of university sports resources routing, network.

1.2.4 It is to realize the resource management between the competent department and information flow, integrated resources information meet controlled access services, personalized access services, real-time access and single sign-on access service sharing requirements.

\section{SPORTS RESOURCES SHARING PLATFORM CONSTRUCTION PROCESS}

\subsection{Three stages of the construction of the sports resources sharing platform}

2.1.1 Develop multiple management systems of socialization of college sports resources sharing platform, including the Changchun university social sports resources sharing platform management measures for running, the system of Changchun university sports resource socialization open management, the department of Changchun university sports resource sharing management interim measures ", etc., with strict rules and regulations to promote the realization of the socialization of college sports resources sharing service, regulations involved in the collaboration of the Shared resources of colleges and universities have a responsibility to bear the mass sports demand, set up by the MPCSC, education, science and technology commission and other departments and departments such as colleges and universities sports socialization of Changchun university sports resource sharing management committee, hire a committee of experts in the field of relevant experts, establish service center of Changchun university social sports resources sharing platform.

2.1.2 Sports resource sharing software system development and research, and application of network information technology, access to comprehensive, accurate sports resources and management of original data, make the university sports resource sharing platform to be carried out in accordance with the system management.

2.1.3 Through information technology innovation, management innovation, mechanism innovation, and extensive investigation of college sports resources, to build a more humanized and easy and standardized system of sports resources sharing platform.

\subsection{The technical features of college sports resources platform}

\subsubsection{With information resources sharing, realizing the sharing of sports resources.}

Information sharing is the basis and premise of university sports resources sharing, and promote the Changchun university sports resource sharing service socialization, and jilin university, northeast normal university, Changchun university of technology, Changchun university of science and technology, jilin agricultural university, jilin construction engineering institute, college of jilin agricultural bank management to build research and development of sports resources test service base, such as establishment of sports resources sharing portals, solve the problem of resource information block, the portal website, can browse the information about the schools sports resources, the formation of resources scattered layout optimization management, information data centralized management.

\subsubsection{Relying on the information management system, and promote social sports resources services.}

Use the Internet operating system, relying on the college sports resources sharing platform, base of research and development of each service market operation mechanism reform, through the innovation market operation and service mode, realize the whole sports resources open to the whole society, with resources, with the market, play a connecting link role of social demand and resource service. Information management system covers the basic information management, information sharing resources development, use open reservation, using real-time monitoring level, such as a comprehensive management, information resources and meet the demand of market, improve the efficiency of management and socialized service level.

\subsubsection{Standard service management, promote sports resources platform service ability.}

Prepares the Changchun college sports resources sharing platform open service catalog. The social from all walks of life in order to fully understand and use open sports resources, and according to the 
resources into venues, facilities, teaching and competition, such as four parts, introduced the experimental service platform of service function and characteristic, as a social use of sports resources service practical guide. Including venue functions, facilities, venues of concrete floor, management information and contact way, teaching courseware, etc., and can always view the work schedule and training game schedule, through the Internet booking service. Establish college sports propaganda display and service window, the operation of the open is to realize the information resources sharing platform. Through information service network construction, form systematic, network, scale, specialization of the college sports resources open service system.

\subsubsection{Strengthen the supervision and management, open incentive mechanism.}

Through policy guidance, protocols and mechanisms, strengthen internal management and operation of college sports resources platform, to establish a scientific and reasonable evaluation index system of performance evaluation was carried out on the base and field service platform, applies a system of rewards and punishment incentive.

\section{THE SOCIALIZATION OF UNIVERSITY SPORTS RESOURCES SHARING PLATFORM CONSTRUCTION FUNCTION}

\subsection{With the modern network information technology support to realize sports resources sharing}

By means of modern information technology and network technology, adhere to the principle of "resource sharing, transparent use", in the management platform, all of the sports resources in guarantee under the condition of the school normal teaching order, actively create conditions to carry out sports venues open to the social work, service, serve the society, the school constantly improve venues utilization; With the surrounding community and residents to establish good communication channels, and adopt suitable model, prompting the school sports venues open to the community for a long time; The accuracy of the data information platform, such as the location of the site and open time, open way, and the basic situation of human resources, etc., realize the college sports resources sharing ${ }^{[5]}$.

\subsection{Bridge of effective utilization of sports resources and provide powerful support for the mass sports work}

College sports facilities open to the society, serve the society, serve the people, is the need of vigorously carry out the national fitness campaign, is the inevitable choice of accelerating the development of public sports [3]. Resource sharing platform for integration of resource allocation, form virtual centralized management, to provide information services to take part in physical exercise personnel, to hold the unit resource and set up a bridge between use of resources, effectively solve the problem of the information is not clear, and the bridge of communication with the outside world, expand service socialization of university sports facilities of foreign cooperation, give full play to the colleges and universities has the resources advantage, improve the socialization of college sports facilities service specialization and characterization of the level. Is a major measure for strengthening public sports service, and is the necessary requirement of optimizing the government public service function, to carry out the national fitness campaign, strong support to create a conservation-minded society.

\subsection{Improve the management system, improve the economic benefit}

Colleges and universities on the basis of the original sports resources regulation reform, deepening management system to adapt to the development of mass sports management system in the new period, gradually taking the path of social development, mainly provide sports resources sharing service for as long as the form, and thus to formulate management system should be based on the service, for the masses to provide public welfare and welfare and mutual service system of ${ }^{[4]}$.To reform sports venues management mechanism, enliven the sporting events as a starting point, through the platform to explore cooperative system, leasing, joint and other forms of management, improve the radiation of college sports venues and development potential, and optimize the allocation of resources between colleges and universities, to achieve the best combination of universities and society. Perfect operational mechanism and management system, enhance the utilization of college sports resources and competitive ability, to colleges and universities to create a certain economic benefits.

\subsection{Show the features of college sports resources and advantages, for the masses to provide more quality services}

Typical of natural and human resources of colleges and universities, the sports facilities in the quantity, type, size, equipment level and other advantages, play a positive role in the development of social mass sports. Give full play to its role mainly influenced by three factors, the first pair the openness of the society, the second is the open form, the third is its own operating conditions [6-7]. Openness to expand in order to alleviate the lack of sports facilities right now; Open form features and 
advantages mainly positioning and the sustainability of the future sports development; Sports venues by entrepreneurship, public welfare to the profit-making transformation, reform the management system and perfect management system, and provide many kinds of public services, improve the management level, make guidance to exercise the crowd to get specification, for mass sports work to provide more quality services, features and advantages of college sports resources sharing.

\subsection{Promote the university sports resource market operation mechanism, and promote the development of sports in colleges and universities}

In constructing the sharing platform of sports, with the aid of network digital information production, storage and transmission technology, set up a wealth of information resources guarantee system, the realization of the maximum and the establishment of science and technology literature information resources sharing, and sharing of digital network system, using the platform of information resources makes colleges and universities, society and individuals jointly set up the development of undertakings of physical culture and sports road, take the diversification of investment, sources of funds through various channels, "who investment, who management, who benefit from the investment principles, Changchun university in recent years have been in the sports socialization has made some beneficial attempt, some experience and achievements. Information platform can provide the operator with convenient and efficient information service, to provide a significant role in the socialization of sports resources development and utilization of knowledge and technical support. Make the broadening domain of college sports resources, formed a diversified economy coexist. Enliven the further development of college sports industry, the demand for mass sports related to provide market, promote the development of socialization of college sports resources.

\section{CONCLUSION}

Socialization of university sports resources sharing platform is at present the needs of the rapid development of mass sports, social public sports service innovation management mode, for the mass sports work to provide information service and technical support, aggregation and integration of college sports resources, form the data centralized management, optimize the allocation of resources and resource sharing. Actively help the efficient sports resources, to close, long-term unused resources optimization configuration is reasonable. For private capital, community organizations provide the opportunity into the university sports field, create space for cultivating sports administration of exogenous forces, and take up the sports market services, regulatory, cultivate the responsibility. According to the present stage the be fond of sports, increase funding for the construction of sports venues and facilities, improving environment and service conditions of the sports ground, mining folk sports and promote the emerging sports, organize various forms of training, communication and other activities, improve the distribution of sports venues, reduce operating costs, creating economic benefit is remarkable. Broaden the marketization of sports resources exchange and the cooperation between universities and provide support for resource requirements. Build system of standardization, standardization of the management, implementation of quality management of the development of sports resources, standardized management, sports management, customer service standard management rules, and for the sports resources to create a market environment. Advocated ", sharing, collaboration, service "concept, to cultivate a good business environment and resource sharing service platform construction are more and more extensive participation and social support, to lay a good foundation for the development of mass sports in Changchun.

\section{REFERENCES}

[1] The central committee of the communist party of China, the state council. The national fitness program outline. 1995.

[2] The central committee of the communist party of China, the state council on further strengthening and improving the sports work in the new period of opinion. 2002.

[3] Xin-guang dong. National fitness large. Beijing: Beijing sport university press, 2003:13. PeiLiXin

[4] The comprehensive well-off society of national fitness service system research]. Beijing: Beijing sport university press, 2006:105-120.

State general administration of sports.

[5] Reform and opening up 30 years of China's sports. Beijing: people's sport publishing house, 2008:133-136.

[6] Simon li. Sports management present situation analysis of fitness entertainment industry in China. Journal of xi 'an sports institute, 2002, 12 (1): 7-9.

[7] Lin-peng xiao. Theory of the concept and the structure of the national fitness service system. Journal of xi 'an sports institute, 2008 (4): 9-13. 